\section{KARMA AS MORAL JUSTICE IN THAI BUDDHISM}

\section{Suwanna Satha-Anand ${ }^{*}$}

\begin{abstract}
This article explores philosophical implications of the Buddhist theory of karma as a framework for moral justice.It investigates in what ways and under what conditions karma delivers justice for the individual.From the analysis of both canonical texts and writings of Thai Buddhist scholars, it becomes clear that the Buddhist theory of Karma implies an understanding of justice as entailing elements of both retributive and consequentialist positions. Lastly, it explores the strengths and the limitations of karma as providing moral justice. This last point indicates a discussion of the necessity of including the collective dimension in any discussion of karma.
\end{abstract}

\section{Introduction}

Does religion offer a theory of justice? If not, why the almost universal concept of heaven and hell as reward or punishment for one's moral acts? In the case of Buddhism, the theory of karma seems to provide a basis for moral justice in a more important sense than heaven and hell. ${ }^{1}$ In this article, I will explore some philosophical implications of the understanding of the Buddhist theory of karma as a theory of moral justice. Questions discussed include:

*Associate Professor, Department of Philosophy, Faculty of Arts, Chulalongkorn University, Bangkok
1.In what ways or under what conditions does karma deliver justice to an individual?

2.Does the theory of karma imply a retributive or a consequentialist position? 3. What are the limitations of understanding karma as moral justice?

4.And finally, whether the concept of karma necessarily involves the collective dimension?

\section{Karma as Moral Justice}

The frequent referring to "karma" as a moral principle which explains various aspects of people's lives, whether difference in wealth, beauty, health, love and death, actually conceals the complexity of the operation of karma. When a concept is often invoked, it does not necessarily mean that it is actually fully grasped. The Buddhist teachings on karma are many and complex, to the extent that it is one of the most difficult teachings to grasp within the whole corpus of Buddhist teachings. Karma is closely related to the concept of Dependent Origination (Paticcasmupada), whose operation is so complex that it gave rise to the hesitation of the Buddha to preach after his enlightenment.

"The Dhamma that I have attained is deep, difficulty to grasp, difficult to follow... for the people who are caught up in the world of pleasures. Dependent Origination is difficult to grasp."

${ }^{1}$ One of the reasons why we could argue that heaven and hell are less important in Buddhism than in a monotheistic tradition, is because heaven and hell in Buddhism are not eternal abodes. They are tentative places to work out your store of merits or demerits. Once your bun and baap are exhausted in heaven or hell, you encounter rebirth, until you achieve enlightenment. 
In order to provide a proper basis for understanding this complicated concept in Buddhism, Phra Sriwisuthimoli (The Venerable Dhamma-pitaka) lays out the following conceptual framework:

First, the Buddha negated two theories, namely, one ascribing suffering or happiness comcompletely to self-action; the other ascribing suffering or happiness completely to action by others. The Buddha put karma on a continuum of inter-related conditions. This is done to prevent possible misunderstanding arising from two extreme positions of ascribing all events to one's own action or to others' actions without considering other related causal links. Second, the Buddha negated the theory of past action determinism, which ascribes all suffering and happiness to past karma.

Third, the Buddha negated the theory of theistic determinism, which explains human suffering and happiness in terms of divine or supernatural intervention.

Fourth, the Buddha negated the theory of indeterminism or

${ }^{2}$ Quoted in Phra Sriwisuthimoli (Dhamma-pitaka), Buddha-dhamma. Bangkok:Social Sciences Association of Thailand, B.E.2514,p.105. All translations from the Thai materials in this article are done by this author. Transliteration of Pali terms in this article follows these commonly used in English, for example, karma instead of kamma, dharma instead of dhamma; except for those quoted from the original Pali Canon.

${ }^{3}$ Ibid.,pp.94-95. accidentalism, which accounts

for human suffering or

happiness in terms of luck or

arbitrary forces. ${ }^{3}$

This conceptual framework should serve as a cautionary note to prevent any misunderstanding of karma as indicating a passive acceptance of one's past karma as totally determining one's present situation. Karma indicates a person's responsibility, while at the same time taking into account other people's actions, as well as other related conditions. This framework has also made clear that karma in Buddhism explains human action in terms of an accountable, not accidental, process of contributing factors. Neither non-cause, nor God or other form of supernatural power can be adequate explanation. However, this framework illustrates the difficulty in understanding karma, as one should also be aware that Buddhism, in denying past action determinism, is not denying the influence of past action in one's present condition. Also, in denying the ascribing of suffering and happiness completely to self-action, Buddhism is not denying the responsibility of the individual. On the contrary, it is clear that, according to Buddhist teaching, the individual in the present condition and his/her past karma are both crucial to the understanding of a person's moral decision and action. The denial of complete responsibility does not rule out the importance of the individual's moral responsibility. It therefore requires great wisdom to discern a proper balance between the completely "yes" and the absolutely "no." The Buddhist theory on karma is poised precisely between these two extremes. In this sense the theory of karma is actually another expression of the doctrine of the Middle Path. 
An adequate understanding of karma is made even more difficult when we consider an insight made by Buddhadasa Bhikkhu on the two levels of understanding karma. First, karma understood in its moral dimension, and secondly karma understood from a purely Buddhist perspective. ${ }^{4}$ Venerable Buddhadasa offers the following explanation. The understanding of karma as indicating "You reap what you sow." (Tham dee dai dee, Tham chua dai chua) is a teaching prevalent in almost all religions. This is karma understood in its "moral dimension." On the other hand, the understanding of karma as indicating the ultimate is a teaching of karma which leads to "going beyond" (moral) karma. A Buddhist needs to aim for a systematic practice which will lead one out of the karmic forces operating in one's life." ${ }^{15}$ This observation forces us to be more aware that an understanding of karma cannot be limited to an explication of karma as simply "moral justice." The ultimate aim of Buddhism is the liberation from the cycle of births and deaths, not to be reborn again to reap the harvest from the seeds that one has sown. On this point Venerable Dhammapitaka concurs with Venerable Buddhadasa by emphasizing the fact that heaven and hell are both simply part of the cycle of births and deaths. ${ }^{6}$ This means that neither hell nor heaven in Buddhism indicates a sense of finality of reward or punishment. Precisely because of this, it could be argued that hell and heaven in Buddhism offers justice proportional to the wrongs committed on earth. ${ }^{7}$

\footnotetext{
${ }^{4}$ Buddhadasa Bhikku, Karma beyond Karma. Bangkok: Atammayo, ND,p.3.

Karma is usually expressed as actions of body, speech and mind. But these three aspects of karma merely indicate the site of each karmic act. The moral efficacy of karma needs to be related to other conditions. On this point, Venerable Buddhadasa has offered a systematic survey of the different categories in which karma may be grouped. The three key categories are:

1) Karma grouped together under a framework of temporal efficacy, namely, karma producing immediate effects, karma producing slightly delayed effects, karma producing delayed effects, and karma cutting off further effects.

2) Karma grouped together under a framework of operational efficacy, namely, karma producing births, karma producing nurturing effects, karma decreasing nurturing effects and karma cutting off prior karma.

3) Karma grouped together under a framework of gravity of efficacy, namely, heavy karma, like killing one's parents or killing an arahant or committing an offense which expels one from the monkhood, repetitive karma, neardeath karma and karma from negligence. ${ }^{8}$

The fact that karma has been put into so

\footnotetext{
${ }^{7}$ Some people would argue that within a monotheistic framework, the existence of hell makes heaven impossible. Also, the fact that hell and heaven are both eternal and thus infinite abodes of punishment and reward for finite moral acts, they cannot offer justice. Please see the arguments in more detail in Charles Seymour's "Hell, Justice and Freedom," International Journal of Philosophy of Religion, Volume 43,No.2 (April1998), pp.69-86.

8Buddhadasa Bhikkhu, Op.Cit.,pp.6-14.
} 
many different categories so that it can be understood seems to suggest a highly complex and complicated operational process. If, for example, we use the temporal, operational and gravity dimension to simultaneously analyze one particular moral act, one would find that to pinpoint exactly "what" would be the karmic consequence of an action, is extremely difficult, if not impossible. If all arisings are interdependent, according to Paticcasmupada, then how does one account for a karmic relationship between one moral action and particular consequences? Take for example, a layperson gets involved in the sale of drugs to innocent school children. This action could be categorized as a grave karma, or as a repetitive karma, but in the temporal dimension, the same action could be a karma which produces immediate effects, or a karma which produces slightly delaying effects, or even a karma which produces much delayed effects. When we consider "much delayed effects" as covering the spans of many more lives to come, not only in this life, then how can one account for moral justice without seriously accommodating the elements of faith and great patience? The justice according to the law of karma is then a long process which lies way beyond a conception of justice limited to the present lives of people. Consider the following sayings by the Buddha:

"Monks, some people commit small offences, and that leads them to hell.Other people commit the same small offences, and that brings about effects, all in the present, moreover, some minor effects do not arise, only the grave ones. Which type of people are those who commit even small offences and that leads them to hell? They are people who have not trained themselves in the body, in the precepts, in the mind, and in wisdom. When they commit small offences, those karma can lead them to hell. (Like putting a lump of salt into a small vessel of water.)

Which type of people are those who commit the same small offences and that brings about effects all in the present, with minor effects not arising, only the grave ones do? They are people who have trained themselves in the body, in the precepts, in the mind and in their wisdom. They are great souls, with dhamma always in their heart. These people, when they commit the same offences, those bad kamma would bring about effects all in the present, with minor ones not arising, only grave ones do. (Like putting a lump of salt into a river.) ${ }^{9}$

From this passage, we can see that effects from the same moral acts, committed by different people, bring about different consequences. The moral background of the individual makes a difference. This principle poses a different dilemma from the understanding of a "universal" principle of justice, such as the one used in law, which generally stipulates the same punishment for the same offence committed by any person in a comparable situation. Although, of course, the actual gravity of punishment, whether it is a fine or imprisonment,

${ }^{9}$ Phra Sriwisuthimoli, Op.Cit.,pp.98-99. Translation by this author. 
takes the "historical" aspect of a person's life into consideration as well. An offender with a past criminal record, would be liable to a heavier punishment than the first timer, for example. However, according to Buddhism, it can be said that karma as "moral justice" operates under a principle with different emphasis. In other words, it seems that the law puts greater emphasis on the sameness of treatment for all people, while the theory of karma puts greater emphasis on differences in effects for the same acts. According to Buddhism, since a person's individual accumulation of karma is necessarily different, the same acts cannot possibly produce the same results in different individuals. The effect of the same amount of salt in a small vessel and that in a big body of water like a river, cannot possibly be the same. Thus, it seems that moral justice in Buddhism is based on the principle that different consequences do result from the same acts. It depends on the specificity of the actor as an individual, not as an equal among others. And karma is a "law" which does not operate from an authorized institution. The monks do not constitute a court of justice to redress moral imbalance. The monks are basically a "field of merit" for people to store up their merit accumulation. They are not agents of moral justice. The law of karma operates in its own course and time.

While the law of karma is very complex and extremely difficult to identify exact consequences for a single act, Buddhism does put great emphasis on the absolute efficacy of the law of karma. The effect of a particular karma is neither money, reputation, nor desirable objects, the real effect of karma rests within the moral act itself. A wholesome act brings about goodness and an unwholesome act brings about evil, complete in the very act itself. ${ }^{10} \mathrm{~A}$ strict efficacy of the law of karma is emphasized in the following passages from the Tripitaka, selected by Venerable Dhamma-pitaka:

"Women, men, lay people and monks should entertain constant reflections that we have our own kamma. We are the recepient of our kamma, we have kamma as our origin, as our generation, as our abode. Whatever kamma we perform, whether good or bad, surely we are to harvest the consequences thereof."

"If you are afraid of suffering, commit no evil kamma in public or in private. If you commit evil kamma, although you could fly away, you would not escape from suffering."

"Whoever commits whatever kamma, whether with the body, speech or mind, that kamma belongs to him. He would bring along that kamma. Kamma is

10 Buddhadasa Bhikkhu, Op.Cit.,p.12. Please see additional details in Dhamma-pitaka, Hell and Heaven for the New Generation, Op.Cit.,pp.137-142.

Please see a related discussion of the reasons why Budhadasa's way of articulating Buddhism would be like a "bitter potion" for Thai Buddhists in Louis Gabaude's "Thai Society and Buddhadasa:Structural Difficulties," in Radical Conservatism. Bangkok:Thai Inter-Religious Commission for Development and International Network for Engaged Buddhists, B.E.2533 (1990),pp.211-229. Buddhadasa's exposition of karma would face the same difficulties, according to Professor Gabaude. 
like a shadow which follows a person wherever he goes." ${ }^{11}$

The analogy of the shadow indicates a necessary connection between a karma and its moral consequence. The emphatic statements quoted above might have been a response to some schools of thought prevalent at the time of the Buddha which would not hold sacred the law of karma. There are several sayings of the Buddha which caution against some people whose teachings run against the efficacy of karma. The Buddha judged those who teach "There is no karma" as the worst kind.

Monks, among woven cloth, kesakampol (Cloth woven from human hair)is the worst kind. This kesakampol cloth would feel cold in the winter, would feel hot in the summer. The color is unattractive, the smell bad, the texture coarse. What does this tell you, monks? Among all the schools, the teachings Of the Makhali-vada are the worst.

Monks, those Makhali people offer teaching and opinion to the effect that "There is no kamma, there is no action, there

\footnotetext{
"Phra Sriwisuthimoli,Op.Cit.,p.105. Please also see a discussion of Buddhist Ethics as an absolutist theory in Wit Wisadavet's "Theravada Buddhist Ethics," The Chulalongkorn Journal of Buddhist Studies, Volume 1 Number 1 (January-June 2002), pp.13-21. Please take special note on page 20 where the author makes an emphatic conclusion, "From the above, some people may come to the conclusion that Buddhism is relativistic, believing that good and evil change according to various factors, but ultimately Buddhism is absolutist."
}

is no effort." (That is, in this world, there is no need to mention the effect of kamma, as there is not even kamma.To act or not to act, all is the same. Action and effort also do not exist.)

Monks, at this time, even though I am the Lord Buddha, I say there is kamma, there is effort. The Makhali people would contest me saying there is no kamma, there is no action, there is no effort.

Monks, people put fishing net at the mouth of a river, not for the purpose of welfare, but for the suffering and destruction of the fish. Likewise, those Makhali People were born to be like those people who put human net for catching people, not for the purpose of their welfare, but for the suffering and destruction of many people." 12

In the judgement of the Buddha, the Makhali school is the worst, for it refuses to give validity to karma and the moral consequences of human actions. If people do not believe in a moral dimension of action, it would be difficult to lead a moral life. A disbelief in a moral life would only bring about suffering and destruction for many. On the other hand, although the law of karma is so complex that it is not possible (with the exception of an enlightened one) to know the exact results, there is a great emphasis on the necessity of this moral law. As a law,

\footnotetext{
${ }^{12}$ Buddhadasa Bhikkhu, Op.Cit.,pp. 277-278.
} 
karma is not only universally efficacious, it offers justice at the level of a specific individual. ${ }^{13}$

\section{Retributive or Consequentialist Karma}

These claims from the Buddhist theory of karma leads to another question, namely, whether the law of karma is offering a "retributive" or a "consequentialist" position. On the one hand, does the motto "Do good, reap good. Do evil, reap evil" indicate a position of "An eye for an eye, a tooth for a tooth"? The term "reap" here does not mean "profit", as in terms of wealth or honor. Rather, it refers to the "real effect of karma inherent in the very moral act itself." If one takes the explanation of Venerable Buddhadasa as a guiding principle, one might arrive at the conclusion that Buddhist ethics indicates a "retributive" position. This line of reasoning would challenge the more traditional understanding that the Buddhist teaching on karma indicates a consequentialist position. According to a more traditional understanding, the term "reap" good or bad cannot be understood without reference to certain results or consequences of an action.

The more traditional understanding of karma as indicating a consequentialist position would lead to a highly problematic situation. In other words,

${ }^{13}$ The failure to offer justice for an individual has been used as criticism against major theories, offering justification for the existence of evil within a monotheistic framework. See a brief presentation of the various theodicies and their criticisms in John Hick's Philosophy of Religion. New Jersey:Prentice Hall International Inc., 1990, Chapter 4. the consequences of one particular act could be directly inferred from the motivation for the act itself, or they could be other consequences which might not have been foreseen by the actor. What could be a criterion which would make a distinction between consequences which must be reasonably within expectation and consequences which could not have been foreseen. This criterion would be crucial to the setting of limits of moral responsibility of a person. In other words, an actor could not be held responsible for those unintended consequences lying beyond his/her "reasonable" knowledge. On the one hand, an actor should be held responsible for consequences which are "obviously" within his/her knowledge. But this "reasonableness" is not easy to establish. Take this case for example. A factory situated along a riverbank continues to discharge toxic waste into the waterway. After some time, the people living near the riverbank begin to get sick. The real motivation of the factory owner might be simply to save cost. He does not intend to "harm" anyone. To what extent is it "reasonable" to expect the factory owner to have knowledge of the toxic wastes? If it is reasonable to expect him to foresee health problems of the people, he/she must be held morally responsible for the harm caused to the people. On the other hand, if it is not reasonable to have that expectation of his knowledge, it would be unreasonable to hold him morally responsible. However, it could also be argued that even without prior knowledge of the toxic wastes, once the effects had become a health hazard for the people, he/she should be held responsible anyway. And yet, even if it is reasonable to hold the factory owner responsible, the punishment for the owner might not be able to deliver the intended 
results. Professor Jonathan Jacobs discusses the problems and serious limitations of the consequentialist position and arrives at the conclusion that oftentimes the "unintended" consequences of a result-oriented theory of justice and the element of luck are so unacceptable that it is difficult to imagine under what condition this theory would be feasible as a theory of justice. ${ }^{14}$

On the other hand, the theory of karma has been explained also as indicating a "retributive" theory whose aim is simply to restore a just balance, or annul unfair advantage, or denounce the values of the behavior of the offender. ${ }^{15}$ If we understand karma in this light, we should also understand that when "suffering is a "result" of bad karma, this suffering as punishment is not meant to bring about certain "better" consequences, but simply to establish goodness. ${ }^{16}$ Karma understood as expressing a retributive position would indicate that the karmic "harvest" is simply to restore the original position. Whether this restoration would lead to other consequences depends on other contributing factors. At least at the moment of one particular moral act, the "Good act completes goodness, the evil completes evil, in the very act itself."

At this point we might not be able to make a definite conclusion as to whether the law of karma actually indicates a retributive or a consequentialist position. Judging from the passages quoted above, it seems that the law of karma

${ }^{14}$ Jonathan Jacobs,"Luck and Retribution," Philosophy, Volume74, No.290,1999, pp.535-555.

${ }^{15} I$ Ibid.,pp.535-536.

${ }^{16} \mathrm{Ibid}$.,p.550 "..Thus the punishment has a telos, but the telos is not so much to produce good as it is to establish goodness." implies elements of both theories. Logically speaking, this observation might prove to be unsatisfactory, as it indicates an inconsistent position. However, we have to keep in mind that the moral purposes of Buddhism carry a much broader spiritual concern than a general philosophical project. It is important to note that Buddhism's major objectives are not to create a philosophical system of moral justice. Buddhism needs to establish a definite relationship between a moral act and its consequences. The relationship between the two cannot be decided on purely "logical" ground. The extent of religious practice, the degree of merit accumulation of a person is of great relevance in deciding the consequences of an act. The specific conditions of a particular situation also contribute to the "resulting process" of a particular moral act. Buddhism establishes its claims within the following limits:

$$
\begin{aligned}
& \text { "Regarding the Buddha's } \\
& \text { position on the moral efficacy } \\
& \text { of karma, there is the following } \\
& \text { analogy. Whatever seeds one } \\
& \text { sows, one reaps the harvest } \\
& \text { accordingly. If we sow the seeds } \\
& \text { of white karma, we will be } \\
& \text { rewarded with white results. If } \\
& \text { we sow the seeds of black } \\
& \text { karma, we will be punished with } \\
& \text { black results. This is called a } \\
& \text { direct inheritance, most } \\
& \text { appropriate to the actions } \\
& \text { performed by people. These } \\
& \text { actions would result in the } \\
& \text { distinction between good and } \\
& \text { bad people. This is the law of } \\
& \text { karma in its moral } \\
& \text { dimension."17 }
\end{aligned}
$$

On the one hand, Venerable Buddhadasa

\footnotetext{
${ }^{17}$ Buddhadașa Bhikkhu, Op.Cit.p.,p.17.
} 
coined the phrase "Do good, good is complete. Do evil, evil is complete. All in the very act itself," which indicates a retributive dimension. And yet, in the above passage, Venerable Buddhadasa wished to emphasize the consequentialist position. If we sow the seeds of corn, corn we will reap. If we sow the seeds of rice, rice we will reap. However, whether the rice or the corn will produce a good harvest or not does not depend only on the "nature" of the seeds themselves. The conditions of the soil, temperature, moisture, sunshine, pests, etc., are all contributive factors which all help decide whether the harvests will be good, or even whether a harvest is possible at all. In this way, Buddhism emphasizes the "certainty" of the results; while at the same time, points to the complex and dynamic environment which ultimately will produce results in an uncertain way. Viewed in this way, karma is a theory of moral justice which places "certainty" into an on-going process of uncertainty.

According to the Buddha, "If a brahmin was to say, "I have seen people who have abstained from taking life, abstained from stealing, who are without a revengeful mind, with right view, who after death from destruction of the body, have entered hell." I accept the saying of such a brahmin. However, if that brahmin was to say, "You, noble one, all people who have abstained from taking life, abstained from stealing, who are without a revengeful mind, with right view, all of them after death from destruction of the body will definitely enter hell." I do not accept the saying of such a brahmin. ${ }^{\prime 18}$
It is clear from this that Buddhism accepts the position that some morally sound people go to hell, but does not accept that all morally sound people will enter hell after death. From this passage it is interesting to note that Buddhism seems to go beyond a common expectation (or hope?) that a reasonably virtuous person (someone who has abstained from taking life, stealing, etc.) would automatically go to heaven. On the contrary, we learn from this passage that there is always the possibility that a morally sound person could go to hell after death. The Buddha made an explicit acceptance of this possibility. This first response from the Buddha should serve as a clear reminder for people who donate money to a temple in the hope of gaining heaven. Even people who actually practice the precepts, not only making material donations, have to face the possibility of hell. Perhaps one could understand this passage as indicating the complex working of the law of karma, which certainly produces results, but oftentimes in an uncertain way.

\section{Collective Karma}

One of the major concerns relating to the understanding of karma in Thai society is the fact that karma is understood, not only primarily, but perhaps exclusively, in terms of the individual dimension. Although Phra Sriwisuthimoli has reminded us that karma is one of the factors in an on-going process of Paticcasmupada, which means that the moral action of an individual cannot fully account for the consequences thereof, there is, however, no denial that within a Buddhistic Thai worldview, karma has been understood to indicate

${ }^{18}$ Ibid.,p.267. 
the individual's moral acts or his/her personal store of merits. This individual dimension is so much emphasized that the collective dimension of karma has been completely eclipsed. The Buddha said:

"The learned who have seen

Paticcasmupada, who understand karma and its consequences in its true light, would come to see that the world proceeds according to kamma. Beings go on according to their kamma. Beings are all held together with kamma. It is like the wedge of a cart which is moving on. ${ }^{\prime 19}$

Of course, in order to hold the individual responsible for his/her moral acts, an emphasis on the individual aspect of karma needs to be put forward. The supernatural world should not be held responsible for the workings of men in the world. On the other hand, this same emphasis could also pose another problem concealing the collective dimension or the "being-togetherness" of all lives through karmic forces. All too often, we do not "see" the social or collective dimension of karma. In the analogy of the wedge of a cart, we can see that all components of a cart help decide the appropriate function of the wedge. In this sense, individuals as a collective whole help decide the proper function of the wedge. On the other hand, the nature and direction of the collective movement of all beings are being decided by the wedge as well. It is interesting to note that in the original version of Buddhadhamma Venerable Sriwi- suthimoli did not discuss "collective karma." We can find a treatment of this topic in his more recent writing. He indicates that a society's customs and conventions which hold a society together, are "collective karma." This collective karma helps shape the beliefs and thinking of the members of that society. ${ }^{20}$ Apart from the three poisons of "greed, anger and delusion" we have other "symptoms of passion" which have far-reaching effects on a society. They are:

Tanha: passion for self-profit Mana: desire to subordinate others Thiti: attachment to certain fixed ideas ${ }^{21}$

Venerable Dhamma-pitaka gives several examples of "social karma," namely, corruption, drugs, environmental degradation, and authoritarianism. Authoritarianism is a sign of tanha and mana, that is, a desire to subordinate others for one's own self-profit. When there is authoritarian rule, the whole population are also responsible. This is because the chain of causation which makes authoritarian rule possible rests with everyone in that society. Authoritarianism cannot be accomplished by just one person. "Everyone is karmically responsible."22 This fresh emphasis on the collective dimension of karma is something "novel" in Thai society. A leading historian and social commentator, Professor Nithi Eaosriwongse, offers the following observation regarding the meaning of karma in Thai society:

Since ancient times, Buddhism has not been a social religion

\footnotetext{
${ }^{19}$ Phra Sriwisuthimoli, Op.Cit.,pp.103-104.

${ }^{20}$ Bhikkhu P.A.Payutto, Good, Evil and Beyond:Kamma in the Buddha's Teaching (Tr. By Bhikkhu Puriso) Bangkok: Buddhadhamma Foundation,1993,p.68.

${ }^{21}$ Ibid.p.61. The title of this chapter is "Social Kamma"

${ }^{22}$ Ibid.p.69.
} 


\begin{abstract}
for Thai society. As there were different religions of the spirits which already took care of social regulations. Thai

Buddhism has placed greater importance for the spiritual development of the person. ${ }^{23}$
\end{abstract}

It is interesting to note that the social dimension of karma is an aspect whose emphasis has been late to come to Thai Theravada Buddhist society. One might be able to say that if karma is a moral theory at all, it needs to address the collective or interpersonal dimension. This is because any moral offence is an offence against some other life. Even if it is a "purely" self-inflicted harm which might not cause any grief to anyone else, it could still be considered an act against one's parents who have made sacrifices in bringing one up. Moreover, it could be that a total emphasis on karma in its individual dimension could bring about social apathy, and by implication, lack of social engagement or collective responsibility for the community or the people as a whole.

From another perspective, it could also be argued that the formation process of an individual necessarily involves a medley of other lives. The karmic force of the parents, perhaps not directly and totally "transmitted" to the children, would be intertwined with the karmic formation of a child in a very important sense. This child, after years of up-bring-

\footnotetext{
${ }^{23}$ Nidhi Eaosriwongse, Budddhism in Changing Thai Soceity, Bangkok:Komol Kheemthong,B.E.2543,p.28

${ }^{24}$ Please see an interesting presentation of this argument in Arvind Sharma, The Philosphy of Religion: A Buddhist Perspective. Delhi:Oxford University Press, 1995,pp.178-180
}

ing by the parents, becomes an individual. Without this dimension of collective karma, it would be very difficult to explain the formation of an individual as a member of a social group. Without some concept of collective karma or collective moral responsibility, it would be very difficult to explain, for example, the physical suffering of a two year-old who suffers from an excessive lead level in the blood due to the irresponsibility of drivers and the government agency which is supposed to take care of the lead level in the air in urban Bangkok. The traditional explanation of all misgivings as a result of the person's own past karma would seem greatly inadequate and unjust.

However, there are some scholars who still emphasize the individual dimension of karma. It has been argued, for example that, if the Buddha had such a communal concept of karma, the idea of group karma should have found an important place at least in early Buddhism. But this does not seem to be the case. On the contrary, the Buddha seems to see in karma an explanation of the differential of human beings rather than their solidarity. ${ }^{24}$

\section{Non-concluding Note}

The discussion so far raises questions rather than offers conclusions. The theory of karma in Buddhism is certainly an attempt to offer moral justice for the rights and wrongs of the individuals. However, karma's inherent relation with rebirth places it beyond the epistemic scope of a philosopher to offer any consistent explanation. It is interesting to note that a belief in God is negated on the grounds that a creator God would be inconsistent with injustice in the world. And this is a Bud- 
dhist position, not only a well-rehearsed dilemma within the monotheistic tradition. Thus, the Buddha said,

"If God (Brahma) is Lord of the whole world and creator of the multitude of beings, then why (1) has he ordained misfortune in the world without making the whole world happy, or (2) for what purpose has he made the world full of injustice, deceit, falsehood, and conceit, or (3) the Lord of creation is evil in that he ordained injustice when there could have been justice." 25
Absence of justice where it could have been, is cited here as one of the arguments against a belief in a creator Deity. In this sense one could argue that the Buddhist theory of karma, instead of God, is an explanation for the evils and injustices in the world. Human beings are brought to the center stage of moral responsibility, for themselves and perhaps for the rest of the natural world as well. However, the Buddhist recognition of the vastly complex process of interdependent origination makes it unwise to pinpoint exact consequences for a moral act. A moral effect is surely to take place, but the nature and the temporal framework of that effect remains to be confirmed only by an enlightened one.
${ }^{25} \mathrm{Ibid}$.p. 167 . This paper is an edited version of parts of chapter IV of the author's book, Faith and Wisdom: A Philosophical Dialogue on Religion. Bangkok:Chulalongkorn University Press,B.E.2545. 